Paper

\title{
Honors programs as forerunner for 21st century skills?
}

Pierre van Eijl ${ }^{1 *}$, Ton Peeters ${ }^{1}$, Henmar Moesker ${ }^{2}$, Annemie Dillen $^{3}$, Albert Pilot ${ }^{1}$ and Stan van Ginkel $^{4}$

1. Utrecht University, The Netherlands

2. Hanze University of Applied Sciences, The Netherlands

3. KU Leuven, Belgium

4. Utrecht University of Applied Sciences, The Netherlands

* Corresponding author: p.j.vaneijl@uu.nl

Received: 6 October 2017; Accepted: 26 December 2017; Published: 29 December 2017

\begin{abstract}
Honors programs are frequently regarded as inspiring for redesigning curricula in higher education that incorporate 21st century skills. This explorative study focuses on eliciting students' perceptions regarding their learning gains related to these skills in honors programs. Results demonstrated high learning gains. Moreover, based on students' insights, each honors program can be characterized by its own profile regarding the type of 21st century skills. Further, in two honors programs students were asked to compare their learning gains with the perceived learning in their regular program. The majority of students emphasized that their skills were highly promoted in their honors program in comparison with their regular program. Finally, students suggested varying possibilities to incorporate honors activities in their regular program. However, from a curriculum design perspective, adjustments are needed to fit the regular groups of students.
\end{abstract}

Keywords: honors program, 21st century skills, biology, interdisciplinary, Holocaust

\section{Introduction}

Are honors programs forerunners for 21st century skills? In interviews in a preceding project, 'The Honours Experience' (Van Eijl \& Pilot, 2016), some honors students mentioned that honors programs are the future for education. Sometimes they have learned typical 21st century skills to a much higher degree than in their regular programs. For example, a national survey on the effects of honors programs in the Netherlands (Allen, Belfi, Van der Velden, Jongbloed, Kolster, Westerheijden, Van Broekhoven, Leest \& Wolbers, 2015) showed that honors students at research universities experience a relatively strong development of their research and presentation skills and also ambition and perseverance 
compared to regular students. Honors students of universities of applied sciences experience showed a relatively strong development of their leadership competencies. To get a better picture of these important skills, we started a project to explore to what degree honors students gained relatively more 21st century skills in their honors programs compared to their regular programs. As a preparation we organized a workshop at the International Honors Conference at Windesheim University of Applied Sciences (UAS) in Zwolle, The Netherlands (June 2017), to present the first results and to discuss them. An additional aim of this project is to discover what students think about incorporating honors activities (involved in learning these skills) into the regular program. Three extra-curricular honors programs with participants from the Netherlands, Belgium, USA, Indonesia, Ireland and Nigeria, joined this project: the Biology honors program of Utrecht University, the Interdisciplinary honors program of the KU Leuven and the International honors summer school Camp Westerbork of Hanze University of Applied Sciences. Questionnaires and observations were used to explore their learning gains and ideas about these skills.

\section{What are 21st century skills?}

21st century skills are often mentioned to describe what students will need to function in and contribute in their professional activities in the 21st century. These are generic skills with related knowledge, insight and attitudes (Thijs, Fisser \& Van der Hoeven, 2014). They are considered necessary in a society that is rapidly changing with computers and technology replacing a lot of human labor, creating new opportunities, digital intelligence (big data), becoming more global and bringing new ethical dilemmas (Colvin, 2015). International researchers (supported by Microsoft, Cisco and Intel) have studied these skills for primary and secondary education and reported on these in the KSAVE-model (Knowledge, Skills, Attitudes, Values and Ethics) (Binkley, Erstad, Herman, Raizen, Ripley, \& Rumble, 2010). In the Netherlands this was elaborated by Boswinkel \& Schram (2011). A Utrecht-based research group on 21st century skills of the Freudenthal Institute, Utrecht University (Universiteit Utrecht, Onderwijsadvies en Training (FSW), 2015) made a model for secondary and tertiary education with the following categories: creativity, problem-solving, collaboration and communication, ICT literacy and self-regulation. Some universities have already incorporated these skills in their policy plans, for instance Windesheim University of Applied Sciences:

- Social and cultural skills, personal and social responsibility, and cultural awareness;

- Critical thinking and analytical skills;

- Demonstrating leadership and taking responsibility;

- Being innovative, inquisitive, creative and flexible;

- Initiative-taking, spotting opportunities and having an entrepreneurial spirit;

- Co-operation, interpersonal skills and problem-solving mindset;

- Communicative, effective, accurate, using modern technology to good effect;

- Being able to find, use and evaluate information and effectively use modern technological aids.

(Windesheim University of Applied Sciences, 2014, p. 12).

\section{Overview of 21st century skills}

In the aforementioned model of the Utrecht research group of the Freudenthal Institute, other models can be recognized but it is still concise. However we made some adaptations in the names of categories to be closer to the reality in Dutch honors education. So the self- 
regulation category has been renamed 'Personal leadership' and 'Crossing borders' became a category of its own. An extra sixth category 'Skills yet unknown' has been introduced to take care of unclear and unexpected skills that may also be needed later in this century. These six groups of skills are visualized in figure 1 . These skills are not completely separate from each other. The skills 'giving and receiving feedback' are for instance related to 'communication', but also to the development of personal leadership and teamwork.

Figure 1: Scheme of six categories of 21st century skills

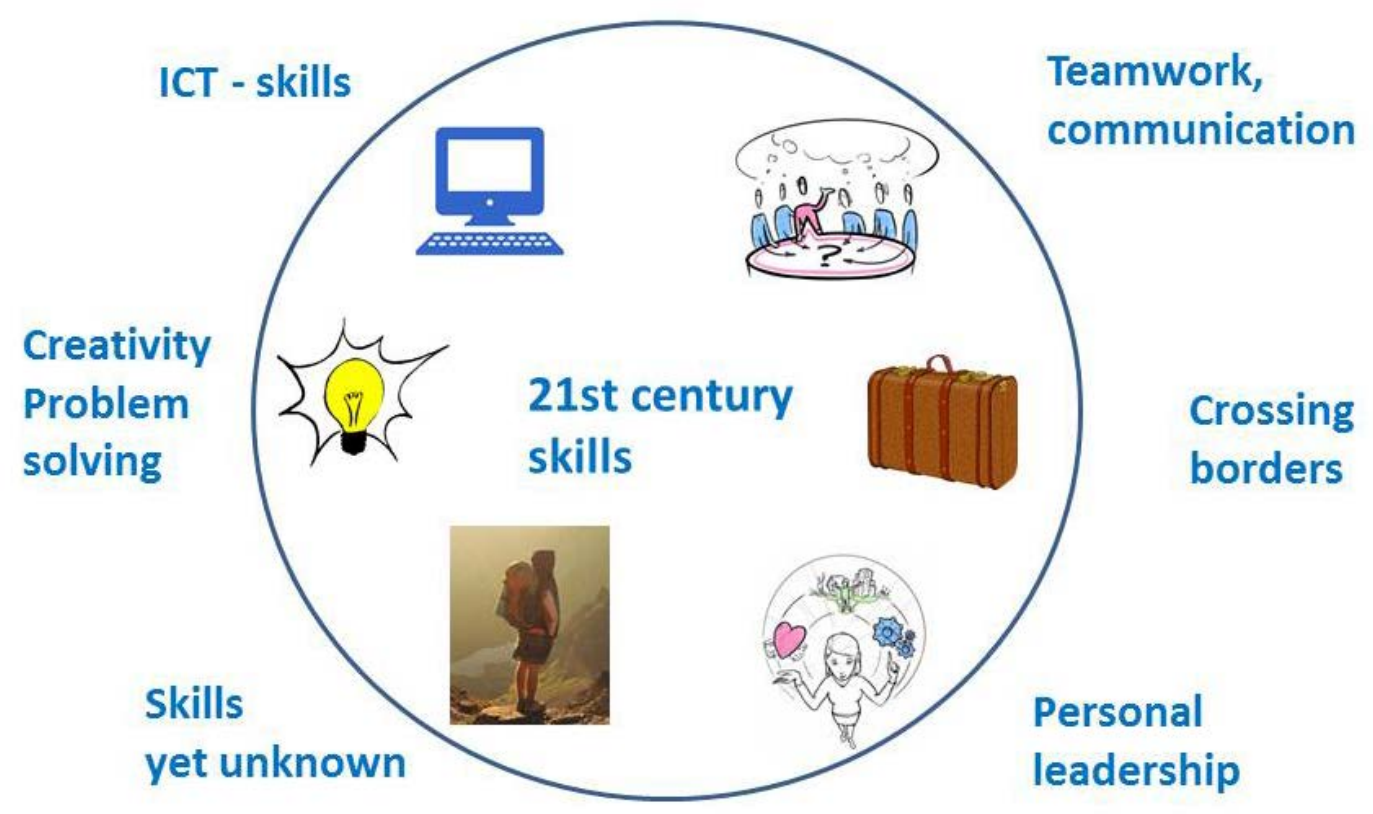

Source of scheme: the authors of this publication

Source of pictures: Pixabay, Unsplash (public domain); Coachcenter (reprinted by permission)

\subsection{Explanation of each category of 21st century skills}

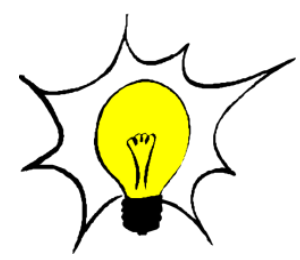

Creativity and problem solving: The ability to create and optimize new ideas, to work in an innovative way, to think critically, to identify, analyze and solve problems and to design something new. (Source picture: Pixabay)

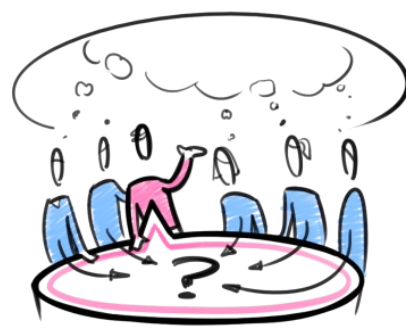

Teamwork and communication: the ability to work in a team and to communicate effectively. (Source picture: $\underline{\text { Coachcenter, reprinted by permission) }}$ 


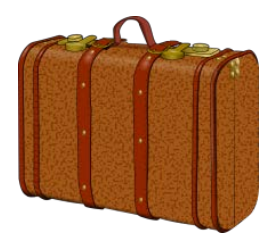

Crossing borders: the ability to work with people from other disciplines and/or cultures/nationalities and the ability to develop a different perspective. (Source picture: Pixabay)

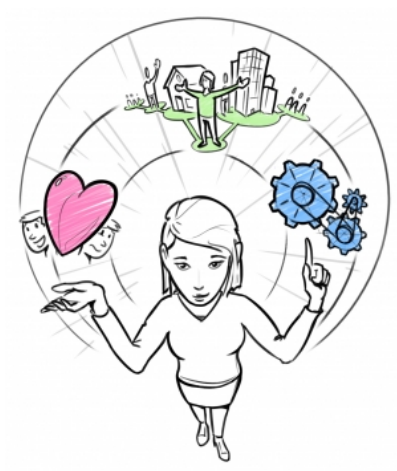

Personal leadership: the ability to arrange your own life and work, to take initiatives, to work on personal development and integrity, and to take responsibility for your own actions. (Source picture: Coachcenter, reprinted by permission)

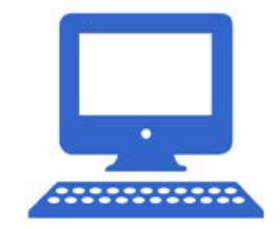

ICT-skills: the ability of effective and efficient use of technology and information, and to understand influences of artificial intelligence on a profession. (Source picture: Pixabay)

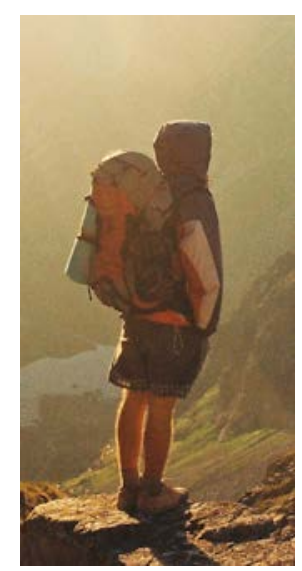

Skills yet unknown: These skills refer to future developments in this century we are not yet aware of and skills that are overlooked until now or only identified incidentally. Some other inventories also emphasize flexibility, adaptability and versatility (EUROlocal, 2017), productivity (including entrepreneurship) and risk-taking (Voogt \& Roblin, 2012). (Source picture: Unsplash / Danka \& Peter) 


\section{Aims and method}

The aim of this study is to explore the opportunities for incorporating 21st century skills in curricula of higher education in the coming years. Based on literature about expected changes in the labor market for graduates of higher education in this century (Colvin, 2015), we think that it is needed to redesign the goals and teaching-learning activities in the curricula of many or all programs in higher education, but until now there is no clear and precise insight in what changes should be made in the many different disciplines. For this reason a first exploration is needed to better understand the problem of what knowledge, skills and attitudes will be necessary in the 21st century curricula in higher education. The results of this exploration can provide a starting point for more detailed and quantitative studies in the different disciplines and cultural contexts. This leads to two goals:

1. to explore the degree in which honors students were stimulated to learn 21st century skills in their honors programs and to ask honors students to compare this to their regular program.

2. to discover what honors students think about incorporation of honors activities (involved in learning 21st century skills) into their regular program.

We focused in this exploration on teachers and students of honors programs in the Netherlands, because we found many curriculum goals, activities and experiences that were linked to discussions in the literature about 21st century skills and the future of the labor market for graduates of higher education in these programs in a previous study. Honors programs are also considered as laboratories for educational innovation in higher education (Wolfensberger, Van Eijl \& Pilot, 2012), so in these programs one might expect to find relevant cases and experiences.

From a previous study, we chose three relevant cases to prepare a workshop on the International Honors Conference at Windesheim UAS in June 2017. Three cases were considered enough for this first exploration. We asked the teachers in the three cases to describe the main characteristics of their course in this perspective, and to ask their students some questions about their involvement and learning gains in 21st century skills after the course. In the first two cases the students answered by way of a questionnaire, in the third case this was impossible. Instead data gathering was done by the teacher, based on the observation of the learning process and the reflection documents of the students at the end of the summer school. The questionnaire was developed specifically for this study by the authors, inspired by the models of section 2, focusing on the goals of this study and adapted to the context of the cases and the expected experiences of the students (see tables 1 and 2 for the questions in the questionnaire regarding 21st century skills).

Because the number of students was low in these cases, we asked all students to answer the questionnaire. In case 1 this involves the students of academic years 2015-2016 and 2016 2017. In the other cases this was 2016-2017.

Data analysis was done for each case separately: case 1 and 2 quantitatively to calculate weighted averages, in order to find what skills students considered (most) important. Because the cases were intentionally quite different, we did not intend to compare the data of the cases. 
The qualitative analysis of the data of the cases was done by the first two authors, focusing on the goals of this study. After reaching consensus, the discussion was continued with the other authors, which led to minor changes and final agreement about the results and conclusions.

\section{Case descriptions}

Before turning to the results of the data collection among students, we first describe the main characteristics of the honors program Biology (UU), the Interdisciplinary honors program of KU Leuven (two courses) and the Summer school Hanze UAS, in relation to 21st century skills.

\subsection{Case 1: The honors program Biology at Utrecht University and 21st century skills} During their first honors year, sophomore students from the honors program of Biology at Utrecht University (the Netherlands) work on a complex project. This project often results in a commercially published book or a comprehensive website. After the start of the project, the teachers no longer give feedback to the students during the further process (only in case of emergency). However, they provide 'just in time' modules, for example about critical thinking and ethics. In addition, students can consult experts on their own initiative. Many important 21st century skills are addressed: collaborating intensively, communicating clearly, arranging effective meetings, developing leadership skills, developing creative, innovative and critical thinking and reflecting. In addition, the task is also a prelude to a piece of education that students have to design and deliver to freshman biology students about the content of their project topic. The group size is 12-19 students. This large group project is a crucial part of the honors program. The task is so complex that students have to work together intensively, divide tasks and jointly take many decisions in order to arrive at a successful result. During this project they should be able to rely on each other. Students have to perform all the activities necessary to produce the book. The project is strongly student-led, and students assign themselves tasks necessary for finishing the project. The assignment comprises an entire academic year, starting in September and finishing in May/June as an extracurricular activity (Wiegant, Boonstra, Peeters \& Scager, 2012). At the end the students organize a symposium where they present their book.

\subsection{Case 2: The interdisciplinary Honors program at KU Leuven and 21st century skills}

The interdisciplinary Honors program on 'evil, retribution and forgiveness' at the KU Leuven (Belgium) is an extra-curricular program consisting of two courses of 3 ECTS points, with one course in each semester (October-January; February-June). The program is meant for about 12 students at the KU Leuven who follow a regular bachelor program (last stage) or master program, within the four faculties of Theology and Religious Studies (1 student), Philosophy (2), Law (3) and Social Sciences (4).

The first course is called 'Conceptualizing evil, retribution and forgiveness', the second course 'Dealing with evil, retribution and forgiveness'. The first part is more centered on conceptual thinking on evil and forgiveness; while the second part includes theoretical reflection as well as concrete involvement in social organizations working on these topics. Various learning activities are scheduled within these courses: excursions (to places such as a museum for remembrance of the Holocaust or to the office of Human Rights Watch); group discussions and close reading of texts from various disciplines; presentations of summaries and reflections on book chapters; keeping a blog together; writing an opinion article for a 
journal; a panel discussion with professors of various disciplines; a film seminar; and reflection about evil and forgiveness in the personal lives of the students.

\subsection{Case 3: The Honors Summer school Camp Westerbork at Hanze UAS and 21st century skills}

Hanze University of Applied Sciences (the Netherlands) and Memorial Centre Camp Westerbork have been working together in the last few years in organizing honors projects that connect lessons from the remarkable history of Camp Westerbork to issues and problems of today's society. One of the projects in this cooperation was a summer school on Holocaust Remembrance in which American and Dutch students worked together in a project connecting past and present day issues in society. In total 11 honors students participated in this summer school, coming from Colorado School of Mines and Texas State University (USA) and Windesheim University of Applied Sciences and Hanze University of Applied Sciences (the Netherlands).

The purpose of the summer school was to further develop personal and social skills of students by providing a project in which international cooperation, working from different perspectives and social responsibility are key components. This was done by connecting World War II history with present day developments and their impact on modern day society. In the summer school students were provided with the opportunity to collaborate with an international cohort to study Holocaust history. Students used these "lessons from the past" to examine, investigate, and critique problems in today's societies concentrating on the theme of bystanders. They created their own project in relation to these complex problems where they could use their initiative and creativity.

Before the actual summer school started, students did research into Holocaust history. This was facilitated with online lectures, readings and assignments. The summer school itself was a 17-day program with excursions to several Holocaust sites in the Netherlands and Germany as well as working on projects on location at Memorial Centre Camp Westerbork. In small groups they created a photo exhibition and a Ted Talk-video about bystanders in the past and what it means to be a bystander in the society of today. The capstone of the summer school was formed by the final presentations of each team's projects. In the summer school an experienced honors teacher worked together with a representative of Memorial Centre Camp Westerbork, together acting as coaches for the participating students.

\section{Results}

\subsection{Results of the questionnaire about 21st century skills}

We asked the students who participated in the honors program of biology in Utrecht (case 1) and the interdisciplinary honors program in Leuven (case 2), first if these programs stimulated them to develop 21st century skills. For the Summer school of Hanze UAS (case 3 ) we rely on teacher observations also including the results of a reflection task performed by the students at the end of their summer school. For cases 1 and 2, table 1 gives an overview of their responses in weighted averages scores. 
Table 1. Honors programs stimulating development of 21st century skills

\begin{tabular}{|c|c|c|c|}
\hline \multicolumn{3}{|c|}{$\begin{array}{l}\text { Question: Did the honors program stimulate you to....? Responses by } \\
\text { students (scale: } 0=\text { no gain; } 1=\text { a little; } 2 \text { = moderate; } 3= \\
\text { remarkable*). }\end{array}$} & \multirow{2}{*}{$\begin{array}{l}\begin{array}{l}\text { Teacher } \\
\text { observations }\end{array} \\
\text { Case 3: } \\
\text { Summer } \\
\text { school } \\
\text { (Hanze UAS) } \\
\mathrm{N}=11^{* * * *}\end{array}$} \\
\hline Questions: & $\begin{array}{l}\text { Case 1: Honors } \\
\text { Biology } \\
\text { (Utrecht). } \\
\mathrm{N}=29^{* *}\end{array}$ & $\begin{array}{l}\text { Case 2: } \\
\text { Interdisciplinary } \\
\text { Honors (KU } \\
\text { Leuven) } \\
\mathrm{N}=6^{* * *}\end{array}$ & \\
\hline \multicolumn{4}{|l|}{ 1. Problem solving } \\
\hline \multirow{8}{*}{$\begin{array}{l}\text { 1. think about real world } \\
\text { problems: } \\
\text { 2. deal with complex } \\
\text { problems: } \\
\text { 3. do research that exceeds } \\
\text { the regular program: } \\
\text { 4. develop your critical } \\
\text { thinking: } \\
\text { 5. think creatively: } \\
\text { 6. enhance your problem } \\
\text { solving skills: } \\
\text { 7. design something new: } \\
\text { 8. work in an innovative } \\
\text { way? }\end{array}$} & medium, 1.90 & very high, 3.00 & high \\
\hline & medium, 1.90 & very high, 2.80 & high \\
\hline & medium, 1.83 & very high, 2.40 & medium \\
\hline & very high, 2.38 & very high, 2.80 & high \\
\hline & high, 2.14 & very high, 2.40 & high \\
\hline & high, 2.07 & medium, 1.60 & medium \\
\hline & medium, 1.97 & high, 2.00 & high \\
\hline & medium, 1.83 & very high, 2.40 & high \\
\hline \multicolumn{4}{|l|}{ 2. Teamwork, communication } \\
\hline \multirow{4}{*}{$\begin{array}{l}\text { 9. work in a team: } \\
\text { 10. learn in discussion with } \\
\text { others: } \\
\text { 11. develop empathy, social } \\
\text { skills and social } \\
\text { intelligence: } \\
\text { 12. improve your written and } \\
\text { oral communications: }\end{array}$} & very high, 2.83 & high, 2.20 & high \\
\hline & very high, 2.79 & very high, 3.00 & very high \\
\hline & medium, 1.79 & very high, 2.60 & very high \\
\hline & very high, 2.52 & high, 2.20 & high \\
\hline \multicolumn{4}{|l|}{ 3. Crossing borders } \\
\hline \multirow{2}{*}{$\begin{array}{l}\text { 13. develop a different } \\
\text { perspective on certain } \\
\text { things: } \\
\text { 14. work with people from } \\
\text { other disciplines and/or } \\
\text { cultures }\end{array}$} & high, 2.10 & very high, 2.80 & very high \\
\hline & low , 1.41 & very high, 2.60 & very high \\
\hline \multicolumn{4}{|l|}{4 Personal leadership } \\
\hline \multirow{2}{*}{$\begin{array}{l}\text { 15. take initiatives and go for } \\
\text { new challenges: } \\
\text { 16. give and receive feedback: }\end{array}$} & very high, 2.48 & moderate, 2.00 & very high \\
\hline & very high, 2.48 & high, 2.20 & high \\
\hline
\end{tabular}




\begin{tabular}{|c|c|c|c|}
\hline \multirow{3}{*}{$\begin{array}{l}\text { 17. develop your personal } \\
\text { and social responsibility: } \\
\text { 18. enhance your capacity for } \\
\text { self-regulation: } \\
\text { 19. work on your personal } \\
\text { development (who am I, } \\
\text { what do I want to be?): }\end{array}$} & high, 2.24 & very high, 2.40 & very high \\
\hline & high, 2.14 & high, 2.20 & very high \\
\hline & high, 2.10 & very high, 2.80 & very high \\
\hline \multicolumn{4}{|l|}{ 5. ICT } \\
\hline \multirow{4}{*}{$\begin{array}{l}\text { 20. use of social media in } \\
\text { team assignments: } \\
\text { 21. improve computational } \\
\text { thinking } \\
\text { 22. check the quality of your } \\
\text { sources on the internet? } \\
\text { 23. enhance your media } \\
\text { literacy? }\end{array}$} & very low, 0.86 & high, 2.00 & high \\
\hline & very low, 0.86 & low, 1.20 & low \\
\hline & low, 1.34 & low, 1.40 & low \\
\hline & low, 1.28 & low, 1.40 & low \\
\hline
\end{tabular}

* Indicative qualifications used to clarify the value of the weighted scores are: very low: 0.801.00; low 1.00-1.50; medium 1.50-2.00; high 2.00-2.25; very high 2.25-3.00

**Respondents case 1 were biology bachelor students from academic years 2015-2016 and 2016-2017; 53\% in second year and $47 \%$ in third year of study. All students were Dutch, except one student from Indonesia.

***Respondents case 2 were 5 males and one female, from different disciplines: Theology and Religious Studies (1), Philosophy (1), Law (3) and Social Sciences (1). Nationality Belgian (3), American (1); Irish (1) and Nigerian (1); bachelor and master students.

****Respondents case 3 were 2 males and 9 females; bachelor students; Nationality:

American (4) and Dutch (7).

\subsection{Results of questionnaire about coaching and a comparison with the regular program} We also asked the students in case 1 and 2 about the coaching of the teachers regarding stimulating the development of 21st century skills and a comparison between their honors program and their regular program with respect to these skills. Table 2 gives an overview of their responses (questions 24 and 25 in the questionnaire).

Table 2: Coaching and development of 21st century skills, and comparison with regular program; replies for cases $1(N=28)$ and $2(N=5)$

\begin{tabular}{|l|l|l|l|l|}
\hline Questions & \multicolumn{4}{|l|}{ Scale and answers in percentages and numbers } \\
\hline $\begin{array}{l}\text { 24 Did your honors coach or } \\
\text { teacher stimulate the } \\
\text { development of these skills? }\end{array}$ & not at all & a little & moderate & $\begin{array}{l}\text { much } \\
\text { more }\end{array}$ \\
\cline { 2 - 5 } & \multicolumn{4}{|l|}{ Case 1: Biology (UU): } \\
\cline { 2 - 5 } & $7 \%(2)$ & $14 \%(4)$ & $68 \%(19)$ & $11 \%(3)$ \\
\cline { 2 - 5 } & \multicolumn{4}{|l|}{ Case 2: Interdisciplinary KU Leuven: } \\
\cline { 2 - 5 } & $0 \%(0)$ & $0 \%(0)$ & $60 \%(3)$ & $40 \%(2)$ \\
\hline
\end{tabular}




\begin{tabular}{|l|l|l|l|l|}
\hline $\begin{array}{l}25 \text { Did your honors program } \\
\text { promote the development of } \\
\text { these skills more than your } \\
\text { regular program? }\end{array}$ & not at all & a little & some skills & $\begin{array}{l}\text { a lot of } \\
\text { these } \\
\text { skills }\end{array}$ \\
\cline { 2 - 5 } & \multicolumn{4}{|l|}{ Case 1: Biology (UU): } \\
\cline { 2 - 5 } & $0 \%(0)$ & $4 \%(1)$ & $54 \%(15)$ & $43 \%(12)$ \\
\cline { 2 - 5 } & \multicolumn{4}{|l|}{ Case 2: Interdisciplinary KU Leuven } \\
\cline { 2 - 5 } & $0 \%(0)$ & $0 \%(0)$ & $60 \%(3)$ & $40 \%(2)$ \\
\hline
\end{tabular}

\subsection{Results of open questions in the questionnaire}

The open questions were:

26. Please give one or more examples of the way your honors coach or teacher stimulated the development of these skills.

27. Which activities of your honors program may be appropriate for incorporation in a regular program of your university?

28. What kind of adjustments on the honors activities are necessary to be able to incorporate them successfully in a regular program? Please give one or two examples of such adjustments?

Results are included in sections 6.4-6.6.

\subsection{Analysis of results case 1: Honors program biology (Utrecht University)}

Development of 21st century skills in the honors program

According to the students their honors program stimulated the development of the following 21st century skills (very high or high scores in table 1):

- Category 1 (Problem solving): critical thinking, thinking creatively, problem solving skills;

- Category 2 (Teamwork, communication) teamwork, learning in discussion with others, improving their written and oral communication;

- Category 3 (Crossing borders): developing different perspectives;

- Category 4 (Personal leadership): taking initiatives and go for new challenges giving and receiving feedback and (high scores) developing personal and social responsibility, enhancing capacity for self-regulation.

The other skills have medium or (very) low scores.

A large majority of $68 \%$ of the students said that their honors coach/teacher stimulated the development of these 21 st century skills in a moderate way (table 2, Q 24). A student explains this score as follows in open question 26: 'We got the assignment to create something as a group project. We decided to write a book. The teachers gave the opportunities and the conditions but we had to regulate the process ourselves.'

\section{Incorporation of honors activities in the regular program}

Students give very diverse answers to this question (Q27), but nearly all students said some activities could be incorporated in their regular program. Some examples are: 'a module about ethics'; 'reading books, more feedback to each other and yourself, critical thinking'; 'individual projects should be stimulated more'; 'a large (intensive) project in which you 
should work together'; 'set up your own project; writing a book! Very educational and really great to do so with a group'; 'reading of popular scientific books'.

However, one student also said 'I don't think any of the activities would fit into the regular program. Adjustments would be necessary.'

Adjustments proposed in case honors activities are incorporated in the regular program: Students proposed a variety of adjustments (Q28), including: 'making it shorter', 'group projects around feasible assignments', 'more workshops', 'a stricter schedule', 'more supervision', 'not a compulsory course but an elective', and 'lower level'.

\subsection{Analysis of case 2: Interdisciplinary program KU Leuven}

\section{Development of 21st century skills}

Students gave the stimulation of the following skills (very) high scores:

- Category 1 (Problem solving): think about real world problems, deal with complex problems, do research that exceeds the regular program, develop critical thinking, work in an innovative way, design something new;

- Category 2 (Teamwork, communication): learn in discussion with others, develop empathy, social skills and social intelligence, work in a team, improve your written and oral communications, give and receive feedback;

- Category 3 (Crossing borders): develop a different perspective on certain things, work with people from other disciplines and/or cultures;

- Category 4 (Personal leadership): develop your personal and social responsibility, work on your personal development, enhance your capacity for self-regulation;

- Category 5 (ICT-skills): use of social media in team assignments.

$60 \%$ of the students said (table 2, Q24) that their honors coach or teacher stimulated the development of some of these skills and $40 \%$ said a lot of these skills. As one student explains ( $Q$ 26): 'The coaches themselves were very active in organizing the program and giving us opportunities to explore. They did not, however, take a leading role in discussing, in the sense that they would not dominate a discussion, rather letting ideas flow freely amongst students once the topic has been launched.'

$60 \%$ of the students said that the honors program (table 2, Q26) stimulated the development of 'some 21 st century skills' and $40 \%$ said 'a lot of these skills'.

\section{Incorporation of honors activities in the regular program}

Many students thought that some honors activities may be appropriate for incorporation in a regular program (Q27). Examples are 'Group debates with smaller groups and interesting professors about certain societal phenomena', 'Exploring the effectiveness of certain measures and considering whether an interdisciplinary approach to a global issue is more appropriate' and 'I think my regular program may benefit from participation in a sociallyengaged manner, which is not encouraged at all'.

Adjustments proposed in case honors activities are incorporated in the regular program Students proposed the following adjustments ( $Q 28)$ : 'I think the use of smaller groups, tutorials, is essential', 'the courses should be taught to students as normal course programs', 'making it more known to the students' and 'the program should be scaled up to be 
incorporated in a regular program, but I am afraid that it will then lose its added value, also because people will then be forced to participate (even if there is no motivation)'.

\subsection{Analysis of case 3: Honors Summer school Camp Westerbork, Hanze UAS, The Netherlands}

\section{Development of 21st century skills}

Students reflected on the summer school (table 1). They mentioned specifically that their critical thinking and creative thinking, team work, developing different perspectives and developing personal leadership have been enhanced by the program.

Incorporation of honors activities in the regular program (teacher observation) Although the summer school as a whole cannot be transferred to regular programs, elements of it may be used, for instance letting students work in multidisciplinary groups and working with assignments that require cooperation, creative skills and using different perspectives.

\section{Conclusion}

In this section, we return to the goals of this study which were introduced in section 4 .

Goal 1: to explore the degree in which honors students were stimulated to learn 21st century skills in their honors programs and to ask honors students to compare this to their regular program.

In all three cases, which are by purpose very different, student data show that the learning of 21st century skills was stimulated in their honors programs. Each honors program had its own profile for the type of skills and the intensity of the learning. However, in all three programs one or more skills related to the categories 'problem solving', 'teamwork and communication', 'crossing borders' and 'personal leadership' have high to very high scores. Students don't report high extra learning gains for ICT skills.

In cases 1 and 2 student data show that their honors program promoted the development of some or a lot of 21st century skills. The student data in cases 1 and 2 also show that the teachers/coaches did stimulate them to learn these skills, but to a moderate degree, as one student explains: 'The teachers gave the opportunities and the conditions but we had to regulate the process ourselves.'

Goal 2: to discover what honors students think about incorporation of honors activities (involved in learning 21st century skills) into their regular program.

Most students in cases 1 and 2 said that some honors activities related to the learning of 21st century skills may be appropriate for incorporation in a regular program. A diversity of examples is given for each honors program. For example, the teacher observations in case 3 point to the following element: letting students work in multidisciplinary groups and working with assignments that require cooperation, creative skills and using different perspectives. Most students think that adjustments are necessary. 


\section{Discussion}

If we consider the results of this exploratory project we have a strong indication that the three honors programs stimulate the development of 21st century skills, or a lot of these skills. For cases 1 and 2, we have strong indications that the honors programs promoted the learning of these skills more than the regular programs. We use the word 'indication' because in the honors biology program quite a big group of 29 students (of two academic years) responded to the questionnaire, but in Leuven only 6 students did. The questionnaire was not used in the third case, where we had to rely on the observations of the teacher. The remarkable development of 21st century skills can also be the case in other honors programs elsewhere, but there is a great diversity in programs. So we expect that each honors program will have its own profile of 21 st century skills. This can give a rich variety of examples of honors activities that have the potential for the learning of these skills.

It is striking that the development of ICT skills did get only one high score (in case 2). But we had to take in to account that students are growing up with ICT and the honors programs cannot teach them much more on those skills. However, we think that the understanding of artificial intelligence will be a major issue in the coming years, which should, in our opinion, not be underestimated.

In the introduction also 'skills yet unknown' are mentioned. Issues such as dealing with ethical dilemmas ('doing the right thing'), personal integrity and awareness of potential implications of own actions may be important 21st century skills.

As mentioned in section 1, we organized a workshop at the International Honours Conference of 2017 in Zwolle, The Netherlands where these results were discussed. The participants of the workshop agreed in discussion about the relevance of this results.

'Honors programs as forerunner for 21st century skills' isn't only a promise and potential but requires also a way in which honors innovations can be adjusted and incorporated in regular programs. Because honors students are the more able and motivated students within the whole group of students who are engaged in the regular program. The adjustments proposed by the students refer to this point. Previous research (Wolfensberger, Van Eijl \& Pilot, 2012) showed that this incorporation is often an informal process where teachers and sometimes students start experimenting with their honors experiences in parts of the regular program. In some universities there is a policy where honors programs are used also as a laboratory of change for the regular program (Wolfensberger, et al., 2012). A problem is that many successful honors innovations in education regarding 21 st century skills are only known in a small circle of direct participants. The knowledge of these educational innovations can be stimulating for many others and it is worth to make them available by using the internet, publications and personal contacts.

\section{References}

Allen, J., Belfi, B., Van der Velden, R.K.W., Jongbloed, B., Kolster, R., Westerheijden, D., Van Broekhoven, K., Leest, B., \& Wolbers, M.H.J. (2015). Het beste uit studenten. Onderzoek naar de werking van het Sirius Programma om excellentie in het hoger onderwijs te bevorderen. Nijmegen: ITS/ROA/CHEPS. Available online: http://doc.utwente.nl/98812/

Binkley, M., Erstad, O., Herman, J., Raizen, S., Ripley, M. \& Rumble, M. (2010). Defining 21st century skills. Melbourne: University of Melbourne. 
Boswinkel, N. \& Schram, E. (2011). De toekomst telt. Enschede: SLO/Ververs Foundation. Available online: http://www.slo.nl/downloads/2011/toekomst-telt.pdf/ (accessed 6 December 2017)

Colvin, G. (2015). Humans are underrated. What high achievers know that brilliant machines never will. Boston: Nicholas Brealey Publishing.

EUROlocal (2017). Inventory of 21st Century Skills and Competencies in a Learning Region. Available online: http://eurolocal.info/resource/inventory-21st-century-skills-andcompetencies-learning-region (accessed 6 December 2017)

Thijs, A., Fisser, P., \& Hoeven, M. van der (2014). 21e eeuwse vaardigheden in het curriculum van het funderend onderwijs. Enschede: SLO.

Voogt, J. \& Roblin, N. P. (2012). A comparative analysis of international frameworks for 21st century competences: Implications for national curriculum policies, Journal of Curriculum Studies, 44(3), 299-321

Universiteit Utrecht, Onderwijsadvies en Training (FSW)(2015). 21ste eeuwse vaardigheden en ondernemerschap. Deelonderzoek, version 20150602. Available online:

http://www.fi.uu.nl/wiki/index.php/21ste eeuwse vaardigheden en ondernemerschap (accessed 13 December 2017)

Van Eijl, P.J. \& Pilot, A. (Eds.) (2016). The Honors Experience, talentontwikkeling door de ogen van de honorsstudent. Rotterdam: Hogeschool Rotterdam Uitgeverij. Available online: https://www.researchgate.net/publication/305215269 The honors experience talent dev elopment through the eyes of honors students synopsis. English version available: https://www.researchgate.net/publication/305213336 The Honors Experience Talentont wikkeling door de ogen van de honorsstudent (accessed 6 December 2017)

Wiegant, F., Boonstra, J., Peeters, A. \& Scager, K. (2012). Team-based learning in honors science education: the benefit of complex writing assignments. Journal of the National Collegiate Honors Council 13, 219-227. Available online:

http://digitalcommons.unl.edu/nchcjournal/364/ (accessed 6 December 2017)

Windesheim (2017). International Honors Conference on 8 and 9 June 2017. Available online: https://www.windesheim.com/about-windesheim/events/2017/january/internationalhonors-conference-2017/ (accessed 12 December 2017)

Windesheim University of Applied Sciences (2014). Windesheim Educational Concept. Zwolle: Windesheim University of Applied Sciences

Wolfensberger, M.V.C., Van Eijl, P.J. \& Pilot, A. (2012). Laboratories for educational innovation: honors programs in the Netherlands. Journal of the National Collegiate Honors Council, 13(2), 149-170. Available online:

http://digitalcommons.unl.edu/cgi/viewcontent.cgi?article=1359\&context=nchcjournal (accessed 6 December 2017) 
Links to the honors programs included in this paper:

Biology honours programme of Utrecht University:

https://sciencehonours.sites.uu.nl/students/biology/

Interdisciplinary honours programme of the KU Leuven:

https://theo.kuleuven.be/en/students/honours-programme

International honours Summer school Camp Westerbork of Hanze University of Applied

Sciences: https://www.hanze.nl/eng/education/summer-courses/hanze-summer-

school/courses/honours-summer-school-holocaust-remembrance/about-honours-summer-

school-holocaust-remembrance 